\title{
Role of Two Commonly Available Plants in Combating Harmful Bacteria
}

\author{
Kalaiyarasi. $\mathrm{L}^{1}$, Fauzia Ahmed ${ }^{2}$ and Mubeen sultana. $\mathrm{D}^{3}$ \\ ${ }^{1,2,3}$ (PG \& Research Department of Zoology, JBAS college for Women/Madras University, India)
}

\begin{abstract}
In the present study an investigation was done to assess the efficiency of Mangifera indica and Acacia nilotica as an efficient antimicrobial agent against most of the pathogenic bacteria. In this study, Methanol and Hexane extracts of leaves of Mangifera indica and Acacia nilotica were evaluated against bacterial strains. The tested micro organisms were Proteus bulgaris, Micro coccus, Shigella, Enterobactor, Salmonella typhi, Listeria, Klebsiella pneumoniae, Bacillus cereus, Streptococcus aureus and E.coli. The antibacterial activity was determined using agar well method. The zone of inhibition of extracts of Mangifera indica was compared with the inhibition zone of extracts of Acacia nilotica. The results showed that the inhibitory effect of Mangifera indica was greater than Acacia nilotica.
\end{abstract}

Keywords: Acacia nilotica, agar well method, antibacterial activity, Mangifera indica, zone of inhibition.

\section{Introduction}

For many years, medicine had depended exclusively on leaves, flowers and barks of plants; only recently have synthetic drugs come into use and in many instances, these are carbon copies of chemicals identified in plants. According to WHO, a medicinal plant is any plant which in one or more of its organs, contains substances that can be used for therapeutic purposes [1].The commercial value of various innumerable drugs and pharmaceuticals derived from tropical forest systems on world wide basis is projected at 20 billion dollars a year [2]. Plants are the cheapest and safer alternative sources of antimicrobials [2-4].

Naturally occurring compounds in higher plants that possessed antimicrobial activity has been demonstrated by many workers. Various micro organisms such as bacteria, fungi, viruses \& protozoa have pathogenic interactions with human beings and cause disease to them. Prevention of pathogens is usually achieved by using chemical preservatives. These chemical preservatives act as antimicrobial compounds which inhibit the growth of undesirable micro organisms. However, the onset of microbes increases the demand for minimally processed, external shelf-life food and reports of chemical preservatives as having potential toxicity demand for food manufacturers to find alternative sources of antimicrobial compounds.

The use of herbs in treatment of animal and human disease has long been established. Most plant extracts have been shown to possess anti-microbial agents active against micro organisms in vitro. These plants contain medicinal properties which make them potent to cure or prevent diseases [5]. The antimicrobial compounds from plants may inhibit bacterial growth by different mechanisms than those presently used. Antimicrobials therefore may have a significant clinical value in treatment of resistant microbial strains [6].

Long before mankind discovered the existence of microbes, the idea that certain plants had healing potential, indeed, that they contained what we would currently characterize as antimicrobial principles, was well accepted. Since ambiguity man has used plants to treat common infectious disease and some of those traditional medicines are still included as part of the habitual treatment of various maladies.

Because of the presence of microbes such as bacteria and fungi in all walks of human life, there is a constant interaction between microbes and human. Microbes are important to the production of many human foods, such as beer, wine, cheese and yoghurt, the development of medical treatment, such as antibiotics and vaccines and the processing of our industrial waste.

Studies in the past decade confirm that the growth of both gram positive and gram negative food borne bacteria, yeast and mold can be inhibited by garlic, onion, cinnamon, cloves, sage and other spices. Effects of the presence of these spices/herbs can be seen in food products such as pickles, bread, rice and meat products. The fat, protein, water and salt contents of food influence microbial resistance. Thus it is observed that higher levels of spices are necessary to inhibit growth in food than in culture media.

\subsection{Mangifera indica}

It contains approximately 69 species. The mango is a fleshly stone fruit belonging to the genus Mangifera, consisting of numerous tropical fruiting trees in the flowering plant family Anacardiaceae. The mango is native to India from where it spread all over the world. It is one of the most cultivated fruits of the tropical world. While other Mangifera species (Eg. Horse mago, Mangifera foetida) are also grown on a more 
localized basis, Mangifera indica - the common mango or Indian mango is the only mango tree commonly cultivated in many tropical and subtropical regions, and its fruit is distributed essentially worldwide.

Mango trees grow up to $35-40 \mathrm{~m}$ tall. The mango tree is long-lived, as some specimens bear fruit after 300 years. In deep soil, the taproot descends to a depth of $6 \mathrm{~m}$ with profuse, wide spreading feeder roots; the tree also sends down many anchor roots, which penetrates several feet of soil. The leaves are evergreen, alternate, simple, $15-35 \mathrm{~cm}$ long and $6-16 \mathrm{~cm}$ broad; when the leaves are young they are orange-pink, rapidly changing to a dark and glossy red, and then dark green as they mature. The flowers are produced in terminal peduncles 10-14 $\mathrm{cm}$ long. Each flower is small and white with five petals $5-10 \mathrm{~cm}$ long, with a mild sweet, odour suggestive of lily of the valley. The fruits take 3-6 months to ripen. The ripe fruit varies in size and colour. Ripe unpeeled fruit gives off a distinctive resinous, sweet smell. The leaves of the mango contain a good amount of mangiferin (xanthone) the natural C-glucoside xanthone mangiferin. The formula is $\mathrm{C}^{19} \mathrm{H}^{18} \mathrm{O}^{11}[7]$.

The leaves have been reported to possess antibacterial activity against E.coli and other bacteria and the bioactive component mangiferin isolated from Mangifera indica is reported to possess remarkable antiinfluenzal activity [8]. The presence of phytoconstituents in the leaf extracts may be responsible for the antibacterial activity of the plant [9]. The freshly prepared extracts were subjected to standard phytochemical analyses for different constituents such as tannins, alkaloids, flavonoids, anthraquinones, glucosides, saponins and phenols [10].

In some instances most of the antibacterial activity would be attributed to the reaction between the active ingredients that is released by the extract with the bacteria that was made to react. The tendency of the nature of variation in activity of both the extracts may also vary due to external parameters like drying, grinding and analysing the extract in the refrigerated condition.

When the extracts were compared before and after drying, in rare cases drying would have reduced the antibacterial efficacy of the extract. When compared to its natural conditions Mangifera indica has been proved to be a very potent cure for most of the diseases in traditional medicine.

\subsubsection{Medicinal uses}

There are many medicinal uses that are attributed to mango. Mango leaves are considered helpful for treatment of diabetes. The tender leaves can be soaked in water overnight and squeezed and taken every morning or else dried and powdered and consumed in the mornings and evenings. Mango leaves are also used in effective treatment of burns.

The seeds of mango should be dried and powdered and can be used for treatment of diarrhoea. This should be given in small doses with honey and cured with the fresh juice of mango flowers which is also used for treatment of diarrhoea. The paste of mango seeds is used for treatment of female disorders like vaginitis and leucorrhoea. The mango bark juice is used to control heavy bleeding during the menstrual cycle in women.

Eating one or two green mangoes help in the treatment of gastro intestinal disorders and helps with digestion and prevention of constipation, dysentery, morning sickness and piles. The juice of mango bark is used as gargle for relief from throat diseases and diphtheria. The juice that oozes out when mangoes are plucked can be used as a relief for bee stings and scorpions bites. Mango leaves are dried and powdered and are used for treatment for excreting renal stones and improving hair growth.

. Mango fruit is believed strengthen the immune system of the human body. Dried mango seed powder can be used as good toothpaste for dental problems and to strengthen the gums. The bark is used in treatment of leucorrhoea, menorrhoea, dysmenorrhoea and other menstrual disorders and eczema. Flowers are used in treatment of dysentery, spermatorrhoea, and they repel mosquitoes.

The gum is warmed with lime, aloe and turmeric for healing sprains and painful joints. Leaves are considered astringent, and used in treating diabetes and cholera. Unripe fruit of mango fruit is rich in vitamin "C" which is equal to that of 6 lemon fruits. It also contains a large number of starch, and acids like citric, malic, oxalic and succinic compounds which in turn increases bile secretion and act as antiseptic in the intestines. They are also said to be wonders in controlling morning sickness, treating heat stroke, constipation and indigestion.

The milky juice of the plant is also prescribed for psoriasis. Scorpion bites and ring worms, while the bark and kernel are used in treating leucorrhoea, menstrual disorders, etc.

\subsection{Acacia nilotica}

Acacia is a genus of shrubs and trees belonging to the subfamily Mimosoideae of the family Fabaceae. The species name nilotica was given by Linnaeus from this tree's best known range along the Nile River. Acacia are also known as thorn trees, whistling thorns or wattles including the yellow fever Acacia and umbrella Acacias. The genus Acacia previously contained roughly 1300 species, about 960 of them native to Australia with the remainder spread around the tropical to warm- temperate regions of both hemispheres. Despite this richness of Acacia species relatively few appeared to have been investigated. As presently defined, a number of secondary metabolites have been reported from various Acacia species [11]. 
Babul (Acacia nilotica L.) is a medium sized, thorny, nearly evergreen tree that can reach up to 20-25 $\mathrm{m}$ height but may remain a shrub in poor growing conditions [12].The trunk is short, thick (1 $\mathrm{m}$ in diameter) and cylindrical, covered with grey bark. The crown may be flattened or rounded. The root system depends on the growing conditions and subspecies: a deep taproot in dry conditions and extensive lateral roots in flooded conditions. The leaves are $5-15 \mathrm{~cm}$ long, alternate and compound with 7 to 36 pairs of elliptical, grey-green, hairy leaflets. Flowers are sweetly scented and bright to golden yellow in colour. The fruits are linear, flattened, narrow indehiscent pods, 4-22 cm long and 1-2 cm broad, dark-brown to grey in colour and glabrous or velvety. The pods contain 8 to 15 elliptical, flattened bean-shaped dark seeds [13-15].

The main chemical property of Acacia nilotica is tannin. Tannic acid is a polymer of Gallic acid molecules and glucose. Tannic acid will hydrolyse in to glucose and Gallic or ellagic acid units. Tannic acid is odourless but has a very astringent taste. Pure tannic acid is a light yellowish and amorphous powder. The formula is $\mathrm{C}^{34} \mathrm{H}^{28} \mathrm{O}^{21}$. The invitro antimicrobial and phytochemical activities $\mathrm{f}$ the crude extract of Acacia nilotica on Camphylobacter coli isolated from Gwagwalada Abattoir was investigated. Hydrolysable tannins, saponins, glycosides, volatile oils, phenols, terpenes, flavonoids and alkaline present in the extract [16].The reaction between the sample and the solvent might have induced greater potency and would have served as an adjuvant to increase the antibacterial activity [17].

\subsubsection{Medicinal and Traditional uses}

Many medicinal and traditional uses are attributed to Acacia. Acacia seeds are often used for food and a variety of other products. In Ayurvedic medicine, Acacia nilotica is considered as a remedy that is helpful for treating premature ejaculation.

A $19^{\text {th }}$ century Ethiopian medical text describes a potion made from an Ethiopian species of Acacia mixed with the root of the tacha, then boiled as a cure for rabies. The ancient Egyptians used Acacia in paints. Smoke from Acacia bark is thought to keep demons and ghosts away and to put the gods in a good mood. Roots and resin from Acacia are combined with rhododendron, acorus, cytisus, saliva and some other compounds of incense. Both people and elephants like an alcoholic beverage made from Acacia fruit.

Some Acacia species are valuable as timber, such as Acacia melanoxylon (Black wood) from Australia, which attains a great size: its wood is used for furniture, and takes a high polish. Some Acacia species are traditionally used locally as fire wood. Acacia gives high opacity and below average bulk paper. This is suitable in lightweight offset papers used for bibles and dictionaries. It is also used in paper tissues where it improves softness. Acacia can be planted for erosion control, especially after mining or construction damage.

Nineteen different species of Acacia in America contain cyanogenic glycosides, which if exposed to an enzyme which specifically splits glycosides, can release hydrogen cyanide in the Acacia leaves. This sometimes results in the poisoning death of livestock. If fresh plant material spontaneously produces 200 PPM or more $\mathrm{HCN}$, then it is potentially toxic. The wood of this species is hard and reddish in colour and most of the browsers eat the leaves. Acacia nilotica has been reported to be very useful in treating diarrhoea and cough in human. It is used as firewood and for fencing posts. The bark exudes an edible gum and is used medicinally according to [18]. The gum can also be used as glue. The Zulus take a decoction of the bark as a cough remedy.

Other parts of the tree were used to treat eye diseases, or as a tranquilizer and even as an aphrodisiac. A root extract was used in the treatment of tuberculosis, impotence, diarrhoea, haemorrhages, toothache, dysentery and gonorrhoea. Extracts made from the leaves are used in the treatment of menstrual problems, eye infections, sores, ulcers, indigestion and haemorrhage. Even as far back as the 1900s when Mrs. Grieves published her book "A modern herbal", the nutritional and medicinal properties of Acacia nilotica were known and appreciated. According to her book, Acacia gum dissolved in equal parts alcohol and water was used for "inflammatory conditions of the respiratory, digestive and urinary tract and is useful in diarrhoea and dysentery".

Purdue University states that the Acacia nilotica bark has historically been used in a wide range of folk treatments, including tuberculosis, diarrhoea, dysentery and leprosy. The bruised leaves were used by the Masaks as poultices on ulcers and they make an intoxicating brew of the roots and bark to give them courage and serve as an aphrodisiac.

In West Africa, the sap, bark and leaves are chewed in the belief that it will prevent scurvy. In Lebanon, the resin is mixed with orange flower infusion because they believe that it will hasten convalescence from typhoid. Egyptian Nubians believe that diabetics may eat unlimited carbohydrates as along as they take regular doses of powdered Acacia nilotica pods.

Mangifera indica and Acacia nilotica has significant antibacterial activity and showed properties that support medicinal use in the treatment of some diseases for mankind. This current investigation was carried out, in order to detect new sources of antibacterial agents against pathogenic as well as medicinally important bacteria. 


\subsection{Plant collection}

\section{Materials And Methods}

The samples used for the antimicrobial tests are Mangifera indica and Acacia nilotica. The fresh leaves of both plants were collected from in and around Urappakkam, Kancheepuram district, Tamilnadu, India.

\subsection{Collection and preparation of Bacterial strains}

The bacterial strains (Proteus bulgaris, Micro coccus, Shigella, Enterobactor, Salmonella typhi, Listeria, Klebsiella pneumoniae, Bacillus cereus, Streptococcus aureus and E.coli) were collected from National Agro Foundation, Anna University Campus at Taramani in Chennai.

Nutrient broth was taken and weighed for $1.3 \mathrm{gms}$. It was dissolved in $100 \mathrm{ml}$ distilled water and it was kept in Autoclave. After autoclaving it was kept in water bath. Then the nutrient broth was poured in to 10 sterilized test tubes in equal amount and cotton plugged using laminar air flow chamber. Ten bacterial strains (Proteus bulgaris, Micro coccus, Shigella, Enterobactor, Salmonella typhi, Listeria, Klebsiella pneumoniae, Bacillus cereus, Streptococcus aureus and E.coli) were inoculated in to the 10 test tubes. Then it was incubated at $37^{\circ} \mathrm{C}$ for $24 \mathrm{hrs}$.

\subsection{Preparation of plant extract}

Fresh Mangifera indica and Acacia nilotica leaves were taken as a sample and washed with distilled water to remove dirt and dried and then it was crushed using mortar and pestle. After that it was weighed for 6gms. The bioactive components were extracted using the methods of (Akerele et al., 2008) with slight modification.

The dried leaf powder was poured in to the cellulose thimble and kept in the Soxhlet extractor. Soxhlet extractor is the principle instrument that is used for the extraction process and it has 3 important parts namely, a condenser, sample holder and a round bottom flask which collected the extract and also it serve as an evaporator. This apparatus is connected to a source of water and power supply. Extraction was done in by adding $150 \mathrm{ml}$ of methanol to one round bottom flask and adding $150 \mathrm{ml}$ of hexane to another flask and then placing the sample in the extractor at $70^{\circ} \mathrm{C}$ for $15 \mathrm{hrs}$.

When the extraction time is complete, the thimble was removed and content were carefully transferred (sample) to the hot air oven and allowed to air dry. Then the flask was allowed to cool in the desiccator. After cooling, the flask containing the sample was measured and the sample was thoroughly washed with methanol. It was then diluted with methanol and hexane and made up to $5 \mathrm{ml}$ and transferred in to a BOD bottle and labelled. It was then kept in a Refrigerator for preservation. This extract can be used for microbiological studies.

\subsection{Agar Well method}

Muller-Hinton Agar (MHA) was used as the medium for bacterial growth. MHA is weighed for 7.6gms and taken in a clean conical flask. It was diluted with $200 \mathrm{ml}$ of distilled water and then plugged with cotton using sterile adsorbent cotton. It was kept in the autoclave for $1 \mathrm{hr}$. After autoclaving it was kept in a water bath to cool.

The Petri plates that were used for preparing the culture medium were sterilized in an incubator at $97^{\circ} \mathrm{C}$. The prepared MHA was poured in to the sterilized Petri plates and allowed to solidify and dry. The incubated micro organisms were swabbed on the surface of nutrient agar plates using sterilized cotton swab. The wells were prepared with the help of a sterilized cork bases. Using a micropipette, $20 \mu 1$ of extract was poured in to I well, and $40 \mu 1$ of extract of same extract was poured in to II well in the plate. The plates were then incubated at $37^{\circ} \mathrm{C}$. After $24 \mathrm{hrs}$ the growth of the micro organism was observed, since not much growth was seen, the incubation was carried for the next $24 \mathrm{hrs}$. The results were observed and the diameter of inhibition zones was measured in $\mathrm{mm}$. The results were tabulated.

\section{Results}

Among the two plant leaves that were tested, Mangifera indica showed maximum inhibition zone. Likewise among the two extracts of Mangifera indica and Acacia nilotica leaves, Methanol extract showed maximum inhibition zone in both the plant leaves. The results of invitro antimicrobial activity of Mangifera indica and Acacia nilotica are represented in (Table1, 2, 3 and Fig.1, 2, 3, 4).

\subsection{Inhibitory activity of Mangifera indica}

The methanolic extract of Mangifera indica showed the maximum antibacterial activity towards Micrococcus which showed $45 \mathrm{~mm}$ of inhibition zone in $40 \mu \mathrm{l}$ (Table 1, Fig.1). The Hexane extract of Mangifera indica showed the maximum antibacterial activity towards Salmonella typhi which showed 44mm of inhibition zone in $40 \mu \mathrm{l}$ (Table 1, Fig.2). When methanol extract of Mangifera indica was compared with Hexane extract of Mangifera indica it showed greater potency. 


\subsection{Inhibitory activity of Acacia nilotica}

The antibacterial activity of methanolic extracts of Acacia nilotica is maximum in Streptococcus aureus which showed $37 \mathrm{~mm}$ of inhibition zone in $40 \mu \mathrm{l}$ (Table 2, Fig.3). The Hexane extracts of Acacia nilotica is maximum in two bacterial strains of E.coli and Listeria. They showed the maximum inhibition zone is $30 \mathrm{~mm}$ in

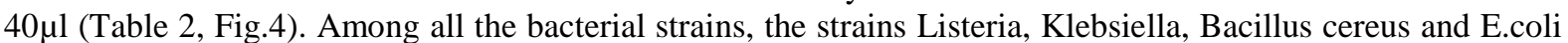
showed the same inhibition zone of $25 \mathrm{~mm}$ against the methanolic extract of Acacia nilotica (Table 2, Fig.4).

The overall Antimicrobial activity in particular the antibacterial activity of Mangifera indica as a potent antibacterial agent was more when compared to Acacia nilotica (Table 3).

\subsection{Statistical analysis}

To verify the results obtained statistical analysis of the inhibitory effect of the active ingredients of the two samples were carried out and the data obtained is represented as Mean \pm Standard deviation. The result that was obtained statistically was similar to the one that was got experimentally. The antimicrobial activity of Mangifera indica is highlighted by the active ingredient present in the extract and also by the mode of extraction, whereas Acacia nilotica does not seen to have significant antimicrobial effect.

\section{Figures And Tables}

TABLE 1: In vitro antibacterial activity of Mangifera indica leaf extract

\begin{tabular}{|l|c|c|c|c|}
\hline \multirow{2}{*}{ Tested micro organisms } & \multicolumn{2}{|c|}{$\begin{array}{c}\text { Methanol extract of } \\
\text { Mangifera indica }\end{array}$} & $\begin{array}{c}\text { Hexane extract of } \\
\text { Mangifera indica }\end{array}$ \\
\cline { 2 - 5 } & $\begin{array}{c}\text { Zone of inhibition } \\
20 \mu \mathrm{l}(\mathrm{mm})\end{array}$ & $\begin{array}{c}\text { Zone of inhibition } \\
40 \mu \mathrm{l}(\mathrm{mm})\end{array}$ & $\begin{array}{c}\text { Zone of inhibition } \\
20 \mu \mathrm{l}(\mathrm{mm})\end{array}$ & $\begin{array}{c}\text { Zone of inhibition } \\
40 \mu \mathrm{l}(\mathrm{mm})\end{array}$ \\
\hline Proteus bulgaris & 33 & 43 & 30 & 39 \\
\hline Micro coccus & 35 & 45 & 30 & 40 \\
\hline Shigella & 30 & 38 & 30 & - \\
\hline Entero bactor & 29 & 31 & 28 & 34 \\
\hline Salmonella typhi & 27 & 39 & - & 44 \\
\hline Listeria & 26 & 33 & 25 & - \\
\hline Klebsiella & 31 & 39 & 22 & 35 \\
\hline Bacillus cereus & 29 & 31 & - & 30 \\
\hline Streptococcus aureus & 27 & 37 & - & - \\
\hline Escherichia coli & 25 & 28 & & - \\
\hline
\end{tabular}

TABLE 3: Antibacterial activity of two plants against pathogenic micro organisms in terms of Mean \pm S.D

\begin{tabular}{|l|c|c|c|c|}
\hline \multirow{2}{*}{ Sample } & \multicolumn{2}{|c|}{ Methanol extract } & \multicolumn{2}{c|}{ Hexane extract } \\
\cline { 2 - 5 } & $20 \mu 1$ & $40 \mu 1$ & $20 \mu 1$ & $40 \mu 1$ \\
\hline Mangifera indica & $29.2 \pm 3.15$ & $36.4 \pm 5.52$ & $16.5 \pm 9.31$ & $22.2 \pm 12.6$ \\
\hline Acacia nilotica & $21.9 \pm 4.06$ & $27.9 \pm 4.81$ & $11.9 \pm 9.19$ & $13.8 \pm 10.42$ \\
\hline
\end{tabular}

$(\mathbf{n}=10)$

TABLE 2: In vitro antibacterial activity of Acacia nilotica leaf extract

\begin{tabular}{|l|c|c|c|c|}
\hline \multirow{2}{*}{ Tested micro organisms } & \multicolumn{2}{c|}{$\begin{array}{c}\text { Methanol extract of } \\
\text { Acacia nilotica }\end{array}$} & $\begin{array}{c}\text { Hexane extract of } \\
\text { Acacia nilotica }\end{array}$ \\
\cline { 2 - 5 } & $\begin{array}{c}\text { Zone of inhibition } \\
20 \mu \mathrm{l}(\mathrm{mm})\end{array}$ & $\begin{array}{c}\text { Zone of inhibition } \\
40 \mu \mathrm{l}(\mathrm{mm})\end{array}$ & $\begin{array}{c}\text { Zone of inhibition } \\
20 \mu \mathrm{l}(\mathrm{mm})\end{array}$ & $\begin{array}{c}\text { Zone of inhibition } \\
40 \mu \mathrm{l}(\mathrm{mm})\end{array}$ \\
\hline Proteus bulgaris & 20 & 26 & 20 & 25 \\
\hline Micro coccus & 20 & 24 & - & - \\
\hline Shigella & 18 & 26 & - & - \\
\hline Entero bactor & 24 & 36 & - & - \\
\hline Salmonella typhi & 22 & 30 & 28 & 30 \\
\hline Listeria & 18 & 25 & - & - \\
\hline Klebsiella & 20 & 25 & - & - \\
\hline Bacillus cereus & 22 & 25 & 20 & 25 \\
\hline Streptococcus aureus & 32 & 37 & 25 & \\
\hline Escherichia coli & 23 & 25 & & 30 \\
\hline
\end{tabular}




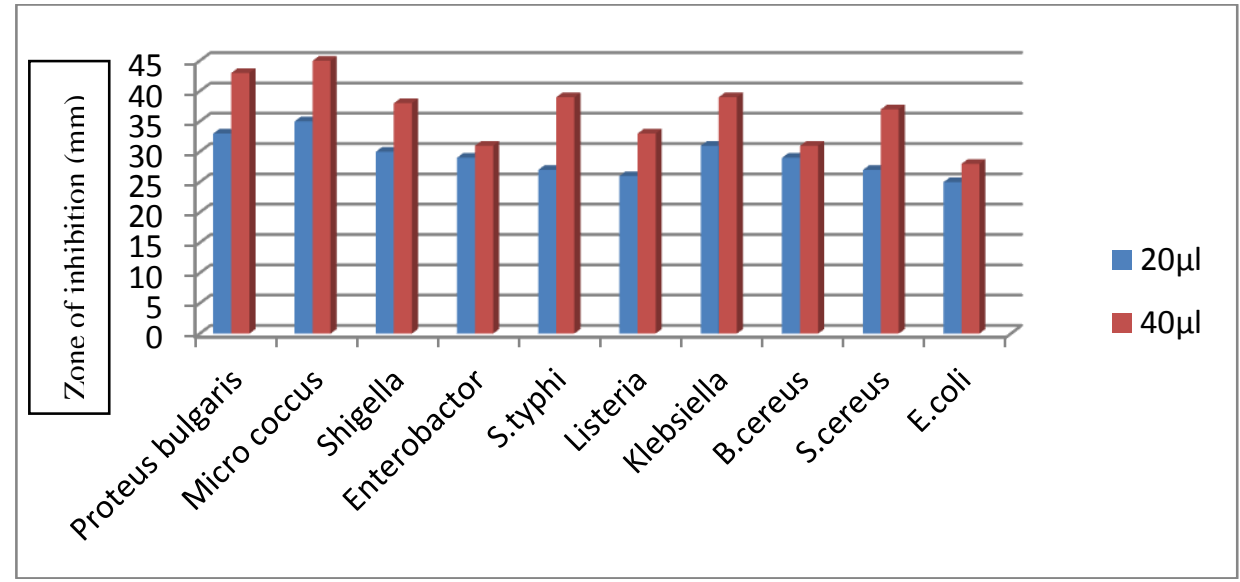

Figure 1: Inhibition zone of Methanolic extract of Mangifera indica.

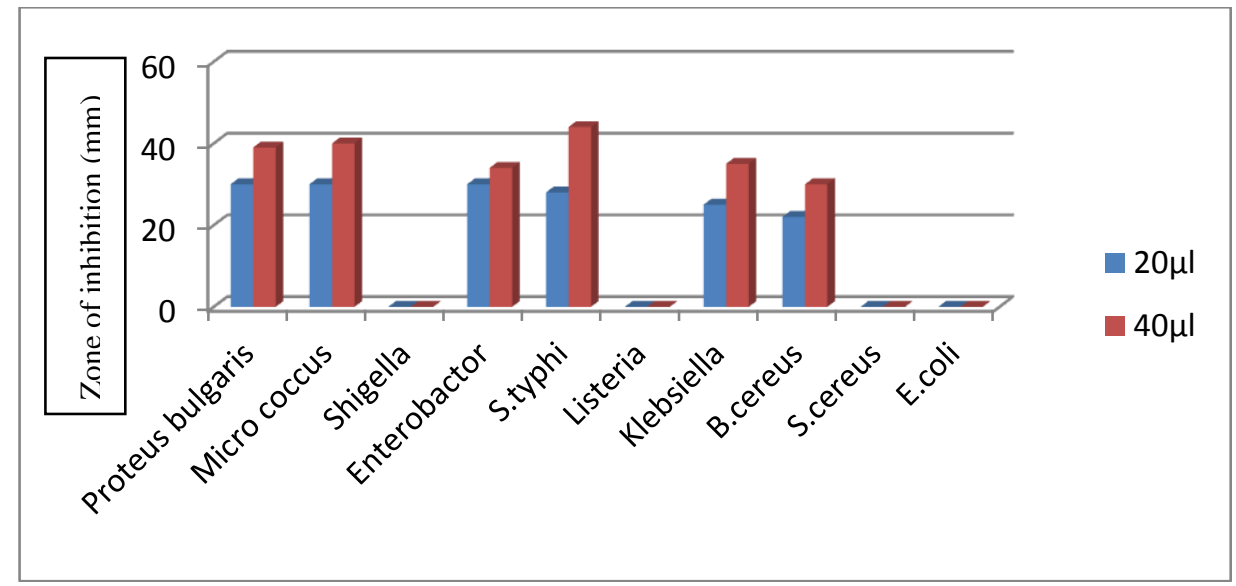

Figure 2: Inhibition zone of Hexane extract of Mangifera indica.

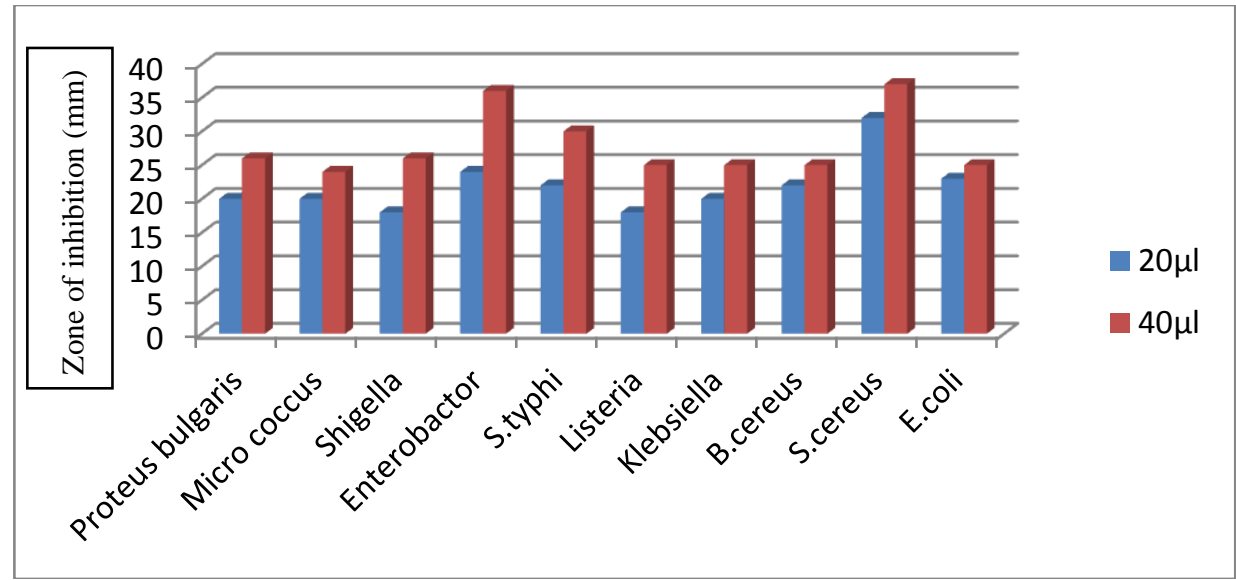

Figure 3: Inhibition zone of Methanolic extract of Acacia nilotica. 


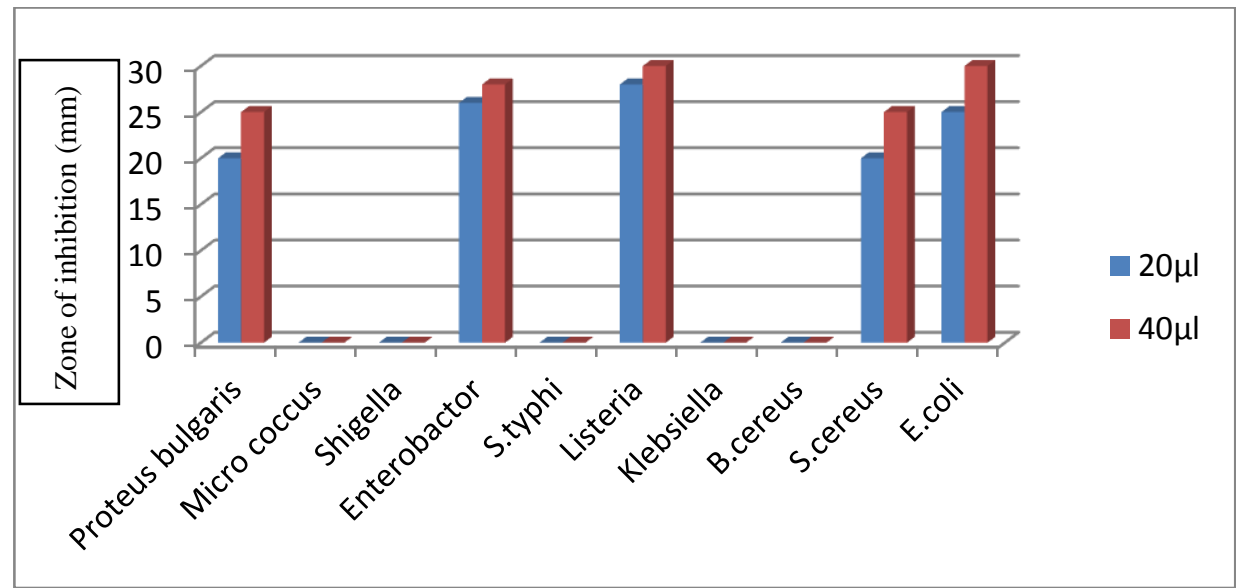

Figure 4: Inhibition zone of Hexane extract of Acacia nilotica.

Plates depicts the Inhibitory effect of Methanolic and Hexane extract of Mangifera indica and Acacia nilotica.
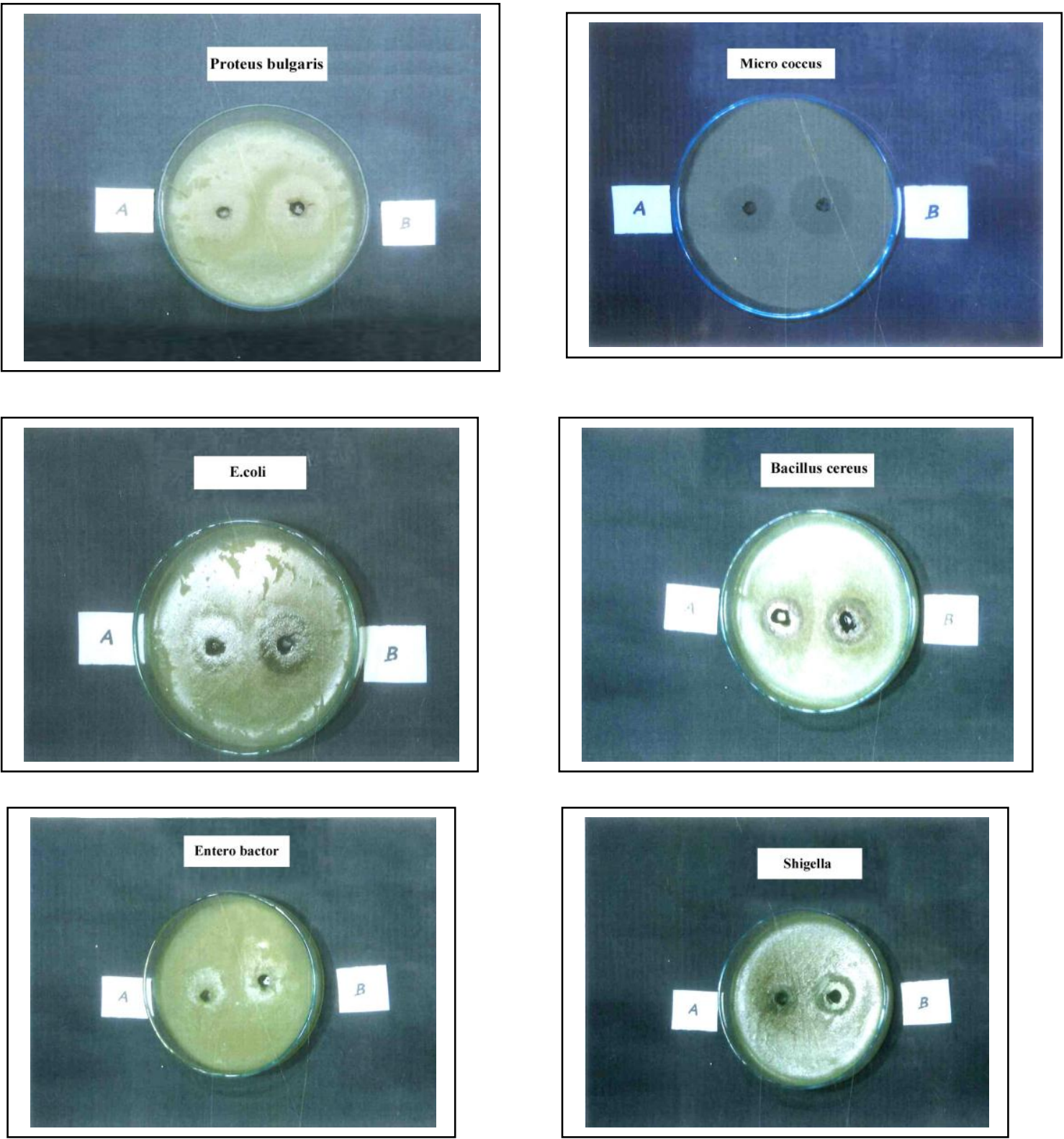


\section{Conclusion}

Mangifera indica and Acacia nilotica have the potential of being an effective antimicrobial agent against micro organisms. Moreover Mangifera indica and Acacia nilotica are widely grown plants and hence they are available easily. This makes them an ideal species to carryout antimicrobial work. In future this can be exploited to harness wide variety of drugs that may be beneficial to mankind. Not only the leaf extract but also other parts of the plant can be evaluated for antibacterial activity. Thus our study concludes that both can be included for combating bacterial infections.

\section{References}

[1] S.A Junaid, A.O. Olabode, F.C.,Onwuliri, A.E.J.,Okworiu, S.E.,Agina, The antimicrobial properties of Ocimum gratissimum extracts on some selected bacterial gastro intestinal isolates, Afri J Biotechnol, 5(22), 2006,2315-2321.

[2] M.D.M. Sharif, G.R. Banik, Status and utilization of medicinal plants in Rangamati of Bangladesh, Res J Agric Biol Sci, 2(6), 2006, 268-273.

[3] C.J. Pretorius, E. Watt, Purification and identification of active components of Carpobrotus edulis L., J Ethnopharm, 76, 2001,8791.

[4] J.H. Doughari, A.M. Ei-Mahmood, S.Manzara, Studies on the antibacterial activity of root extracts of Carica papaya L., Afri J microbiol Res, 2007, 037-041.

[5] A.Sofowora, Medicinal plants and Traditional medicine in Africa, John Wiley and Sons Ltd, Nigeria, 1982, 33-34.

[6] J.N. Eloff, Which extract ant should be used for the screening and isolation of antimicrobial components from plants, J Ethnopharmacol, 60, 1988, 1-8.

[7] S. Murunganandan, S. Gupta, M. Kataria, J. Lal, P.K. Gupta, Mangiferin protects the streptozotocin induced oxidative damage to cardiac and renal tissues in rats, Toxicology, 176, 2002, 165-173.

[8] B. Neon, Medicinal plants in Nigeria private edn, Nig.Coll.Arts.Sci.Tech.Ibadan, 1984, 1-84.

[9] M.C. Marjorie, Plant products as antimicrobial agents, Clin Microbiol Rev, 12(4), 1999, 564-582.

[10] P. Jigna, C. Sumitra, Invitro antimicrobial activities of extracts of Launaea procumbns Roxb. (Labiateae), Vitis Vinifera L. (Vitaceae) and Cyperus rotundus L. (Cuperaceae), Afri J Biomed Res, 9(2), 2006, 89-93.

[11] D.S. Seigler, Phytochemistry of Acacia sensulato Biochem. System. E.coli, 31(8), 2003, 545-873.

[12] Ecocrop, 2012, Ecocrop database, FAO.

[13] C. Orwa, A. Mutua, R. Kindt, R. Jamnadass, S. Anthony, Agroforestree Database: a tree reference and selection guide version 4.0. World Agroforestry Centre, Kenya, 2009.

[14] B. G. Cook, B. C. Pengelly, S. D. Brown, J. L. Donnelly, D. A. Eagles, M. A. Franco, J. Hanson, B. F. Mullen, I. J. Partridge, M. Peters, R. Schultze-Kraft, Tropical Forages. CSIRO, DPI\&F(Qld), CIAT and ILRI, Brisbane, Australia, 2005.

[15] C. W. Fagg, J. Z. A. Mugedo, Acacia nilotica (L.) Willd. ex Delile.. In: Jansen, P.C.M. \& Cardon, D. (Eds). Record from Protabase. PROTA (Plant Resources of Tropical Africa / Ressources végétales de l'Afrique tropicale), Wageningen, Netherlands, 2005.

[16] G.O. Solomon Wisdom and G.A. Shittu, Journal of Medicinal plants Research, Academic Journals, 4(12), 2010 , $1232-1234$.

[17] D. Arora, J. Kaur, Antimicrobial activity of herbs, Intern J Antimicrobial agents, 12, 1999, 257-62.

[18] B. Van Wyk, P. Van Wyk, and B.E. Van Wyk, Photographic guide to trees of Southern Africa, Briza Publications, Pretoria, 2000.

[19] J.O. Akerele, O. Obasugi, M.I. Ebomoyi, I.E. Oboh, O.H. Uwumarongie, Antimicrobial activity of ethanol extract and fractions of the seeds of Garcinia Kola Heckel (Guttiferae), Afri J Biotechnol, 7(2), 2008, 169-172. 